University of Nebraska - Lincoln

DigitalCommons@University of Nebraska - Lincoln

\title{
Analysis of extracted and volatile components in blackstrap molasses feed as candidate house fly attractants
}

\author{
Brian Quinn \\ United States Department of Agriculture, bquinn@gainesville.usda.ufl.edu \\ Ulrich R. Bernier \\ University of Florida, ubernier@gainesville.usda.ufl.edu \\ Christopher J. Geden \\ United States Department of Agriculture, Chris.geden@ars.usda.gov \\ Jerome A. Hogsette \\ United States Department of Agriculture \\ David A. Carlson \\ United States Department of Agriculture
}

Follow this and additional works at: https://digitalcommons.unl.edu/usdaarsfacpub

Part of the Agricultural Science Commons

Quinn, Brian; Bernier, Ulrich R.; Geden, Christopher J.; Hogsette, Jerome A.; and Carlson, David A., "Analysis of extracted and volatile components in blackstrap molasses feed as candidate house fly attractants" (2007). Publications from USDA-ARS / UNL Faculty. 1000.

https://digitalcommons.unl.edu/usdaarsfacpub/1000

This Article is brought to you for free and open access by the U.S. Department of Agriculture: Agricultural Research Service, Lincoln, Nebraska at DigitalCommons@University of Nebraska - Lincoln. It has been accepted for inclusion in Publications from USDA-ARS / UNL Faculty by an authorized administrator of DigitalCommons@University of Nebraska - Lincoln. 


\title{
Analysis of extracted and volatile components in blackstrap molasses feed as candidate house fly attractants
}

\author{
Brian P. Quinn*, Ulrich R. Bernier, Christopher J. Geden, Jerome A. Hogsette, David A. Carlson \\ United States Department of Agriculture, Agricultural Research Service, Center for Medical, Agricultural, \\ and Veterinary Entomology, 1600 SW 23rd Drive, Gainesville, FL 32608, USA
}

Received 6 July 2006; received in revised form 3 November 2006; accepted 6 November 2006

Available online 1 December 2006

\begin{abstract}
House flies are a ubiquitous insect that have the potential to spread many diseases to humans and livestock. Managing house fly populations is accomplished by having desirable baits, traps, and killing agents. Most house fly baits are designed for outdoor use or limited indoor use, and have a foul odor that is not conducive to food preparatory and dining areas. Blackstrap molasses has long been used as a house fly bait, but it is sticky and viscous, making it difficult to handle. This study sought to identify compounds present in blackstrap molasses that might be attractive to house flies, and therefore, provide the public with an indoor bait that does not have an offensive smell and is easy to handle. Indoor bioassays with house flies using 50\% blackstrap molasses diluted in deionized water, a hexane extract of blackstrap molasses, and deionized water, elicited $86.2 \%$, $70.6 \%$, and $13.8 \%$ responses, respectively. Hexane and diethyl ether extracts of blackstrap molasses produced a large number of compounds with widely differing organic structures including substituted phenols, nitrogen and oxygen heterocycles, carboxylic acids, and many other organic compounds.
\end{abstract}

(C) 2006 Elsevier B.V. All rights reserved.

Keywords: House flies (Musca domestica); Blackstrap molasses; Fly bait; Fly attractant

\section{Introduction}

House flies are pestiferous insects that benefit from human colonization, and are readily found on all continents, except Antarctica. These insects are vectors for many diseases including shigellosis [1], enterohemorrhagic Escherichia coli O157:H7 [2-5], salmanellosis [6,7], and cholera [8,9]. Many commercial types of bait are available to attract house flies, but most are designed for outdoor or limited indoor use, due to their malodorous components. There is a great deal of literature on attractants of house flies, perhaps originating with the description of a trap baited with fish heads, watermelon rinds, corncobs and ice cream [10]. Much of this work has focused on identifying components of food odors that can be incorporated into lures [11-14]. Early efforts with baits relied on natural products such as fermented egg slurries [15] or combinations of such items as molasses, milk, yeast, grain, blood, and banana extract $[16,17]$. Brown et

\footnotetext{
* Corresponding author. Tel.: +1 352374 5723; fax: +1 3523745922 .

E-mail address: bquinn@gainesville.usda.ufl.edu (B.P. Quinn).
}

al. [18] tested a range of defined chemical attractant candidates and found that combinations were superior to any individual component tested alone. Mulla et al. [19] reported that blends of trimethylamine, ammonia, indole and linoleic acid were as attractive to house flies as natural food baits. The most common commercial feeding-attractant in use today, Farnam Fly Attractant, was derived by modifying ratios of trimethylamine- $\mathrm{HCl}$ with indole and adding the pheromone muscalure, described below. This attractant is used in granular sugar baits with a toxicant and in toxicant-free liquid jug traps. Geden [20] reported that a $25 \%$ dilution of farm-grade blackstrap molasses was as effective as the Farnam attractant at a fraction of the cost of the commercial lure. In addition to feeding attractants, flies are attracted to the pheromone (Z)-9-tricosene (muscalure) [21,22], and this material is used in most of the commercial scatter baits that are currently on the market.

Molasses has long been recognized as a potent house fly attractant. Nearly 100 years ago, Howard [10] stated that "old" pharmacy treatises included recipes for toxic fly bait that used molasses as the attracting agent. Processing sugar yields a number of different products that are useful for human or livestock 
consumption. The first product made from pressing sugar cane (Saccharum sp.) is called cane juice, and it is clarified with lime and dried to make table sugar, since it contains the highest concentration of sucrose. The second product made from sugar cane is called cane molasses, which is the most common molasses used in cooking and the food industry. Blackstrap molasses, a tertiary commodity of sugar production, is made by thermally concentrating the juice of shredded sugar cane that has been previously expressed to make the other two products, and decanting it into a thick syrup usually containing less than $20 \%$ water [23]. This low water content discourages bacterial growth, and thus, acts as a preservative.

\section{Materials and methods}

\subsection{Extract analysis}

A 240-mL aliquot of a commercial blackstrap molasses feed (Alachua Feed \& Seed Co., Gainesville, FL, USA) was added to a 2-L round-bottomed flask along with $260 \mathrm{~mL}$ of a $3.1 \mathrm{M}$ solution of $\mathrm{NaCl}$ in deionized water and $400 \mathrm{~mL}$ of either hexane or diethyl ether (Burdick \& Jackson, Morristown, NJ, USA). These mixtures were extracted overnight using a continuous liquid-liquid extraction apparatus, and the extracts were concentrated to approximately $150 \mathrm{~mL}$ using a rotary evaporator. All extracts were held at $4{ }^{\circ} \mathrm{C}$ until analysis.

A 1- $\mu \mathrm{L}$ aliquot from each extract was analyzed along with the appropriate solvent blanks using a Trace GC/MS (Thermo Electron, San Jose, CA, USA) equipped with a DB-Waxetr (Agilent, Wilmington, DE, USA) column $(30 \mathrm{~m} \times 0.25 \mathrm{~mm}$ inner diameter, film thickness was $0.25 \mu \mathrm{m}$ ). The GC oven temperature program consisted of an initial hold at $35^{\circ} \mathrm{C}$ for $6 \mathrm{~min}$, then a ramp at $10^{\circ} \mathrm{C} / \mathrm{min}$ to $260^{\circ} \mathrm{C}$, followed by a final hold for $5 \mathrm{~min}$ at $260^{\circ} \mathrm{C}$. The injection port was held at $260^{\circ} \mathrm{C}$ in splitless mode, the transfer line was set to $260^{\circ} \mathrm{C}$, and the carrier gas was set to a constant flow of $1.2 \mathrm{~mL} / \mathrm{min}$.

Compounds were identified by analytical standards (Sigma-Aldrich, St. Louis, MO, USA) when standards were available. Otherwise, very good library matches with a reverse fit of greater than 870 were required along with a retention time that logically fit into the chromatogram. The US National Institute of Standards and Technology (NIST) mass spectral database library (Gaithersburg, MD, USA) was used for tentative compound identifications.

\subsection{Volatile analysis}

A container of mill run blackstrap molasses was received directly from the production line at the United States Sugar Corporation (Clewiston, FL, USA) for analysis of volatile compounds. A 25-g sample was removed from the container and transferred to an opened 1-L Tedlar gas sampling bag (SKC, Eighty Four, PA, USA) and subsequently sealed. The bag with the sample was flushed with humidified ultra-high purity nitrogen and followed by two additional stages of being flushed and evacuated. The sample was then placed into a $45^{\circ} \mathrm{C}$ oven for $30 \mathrm{~min}$ before transferring $600 \mathrm{~mL}$ of the headspace contents of the bag to a 600-mL canister (Entech Instruments, Simi Valley, CA, USA). A 250-mL aliquot of the sample from the canister was analyzed for volatile organic components.

The $250-\mathrm{mL}$ sample was directed at $100 \mathrm{~mL} / \mathrm{min}$ into an Entech 7100A Preconcentrator (Entech Instruments). This instrument uses a 3-trap system to manage both water and carbon dioxide in air samples. The first trap was a glass bead trap that was cooled to $-160^{\circ} \mathrm{C}$. The glass bead trap was then warmed to $10^{\circ} \mathrm{C}$, and the sample was transferred to a Tenax trap that was cooled to $-30^{\circ} \mathrm{C}$. The Tenax trap was heated to $180^{\circ} \mathrm{C}$ and the sample was transferred over three minutes to a fused silica trap that was cooled to $-160^{\circ} \mathrm{C}$. The fused silica trap was then heated rapidly to $100^{\circ} \mathrm{C}$ and the sample was introduced to a GC system. The GC/MS system used for this analysis was a DSQ (Thermo Electron) fitted with a $60 \mathrm{~m}$ DB1-MS (Agilent) column ( $0.32 \mathrm{~mm}$ inner diameter and $1 \mu \mathrm{m}$ film thickness). The GC oven temperature was held at $35^{\circ} \mathrm{C}$ for $4 \mathrm{~min}$ before it was ramped to $290^{\circ} \mathrm{C}$ at $10^{\circ} \mathrm{C} / \mathrm{min}$ and held at $290^{\circ} \mathrm{C}$ for 5 additional minutes. The transfer line was held at $280^{\circ} \mathrm{C}$ for the duration of the analysis and the MS was set to scan from $\mathrm{m} / \mathrm{z} 34$ to 280 at $0.1 \mathrm{scans} / \mathrm{s}$.

\subsection{Biological assays}

Fly pupae were placed in 0.5 -m-square cages ( 5 cages of 400 pupae per treatment) and held for emergence at $25^{\circ} \mathrm{C}, 60 \%$ $\mathrm{RH}$ and constant light with water and food (a mixture of powdered milk, sugar, and powdered egg at a ratio of $6: 6: 1, \mathrm{v} / \mathrm{v} / \mathrm{v})$; an average of 362 flies/cage emerged from the pupae. After approximately $24 \mathrm{~h}$ of feeding ad libitim, the food was removed from the cages for $24 \mathrm{~h}$. Two candidate attractants, $50 \%$ blackstrap molasses diluted in deionized water, a hexane extract of blackstrap molasses, and a deionized water control, were pipetted onto 5-cm filter paper disks. After letting the solvent completely evaporate, a disk was then placed into a $60-\mathrm{ml}$ plastic cup with a screened lid to prevent flies from contacting the test material, and the cup was placed inside a 500-ml plastic container with a lid. A 1-cm diameter hole was cut in the lid and the samples were placed in the fly cages, with each cage receiving the test material and either a water or hexane control for molasses and hexane extract tests, respectively, in paired tests. After $5 \mathrm{~min}$, the hole in the outer container was sealed and the flies were knocked down with $\mathrm{CO}_{2}$ and counted.

\section{Results and discussion}

The results from the analysis of extracted blackstrap molasses (Table 1, Fig. 1) show many different organic components with varying functional groups. A large series of substituted phenols was present in the extracts, and many of them were not satisfactorily identifiable using the MS library. These phenolic compounds are likely breakdown products of naturally-occurring polyphenols, and are created during the process of molasses production [24]. Many heterocycles were present in the extracts including pyrazines, pyrrolidines, furans, and pyranones, along with several different furanones which are known degradation products of simple sugars. At least one furanone in this sample, 2,5- 
Table 1

Organic components extracted from blackstrap molasses

\begin{tabular}{|c|c|c|c|}
\hline Compound name & Retention time (min) & Found in extract & Confirmed by standard \\
\hline Dihydro-2-methylhydroxy-2(3H) furanone & 11.59 & Hexane & $\times$ \\
\hline 3-Hydroxy-2-butanone & 11.96 & Ether & \\
\hline 2,5-Dimethylpyrazine & 12.69 & Ether & $\times$ \\
\hline Trimethylpyrazine & 13.82 & Ether & $\times$ \\
\hline Acetic acid & 14.41 & Both & \\
\hline Propionic acid & 15.45 & Both & $x$ \\
\hline Butanoic acid & 16.86 & Both & $\times$ \\
\hline Furfuryl alcohol & 17.16 & Both & $\times$ \\
\hline Pentanoic acid & 18.14 & Hexane & \\
\hline Propanamide & 18.84 & Ether & $\times$ \\
\hline 2-Hydroxy-3-methyl-2-cyclopenten-1-one & 19.08 & Both & $\times$ \\
\hline Hexanoic acid & 19.34 & Ether & \\
\hline 2,5-Dimethyl-4-hydroxy-3(2H) furanone & 19.44 & Both & \\
\hline Butylated hydroxytoluene & 19.92 & Ether & \\
\hline Acrylamide & 20.22 & Ether & $\times$ \\
\hline 1-(1H-Pyrrol-2-yl) ethanone & 20.63 & Both & $\times$ \\
\hline Furan carboxylic acid methylethyl ester & 21.04 & Hexane & \\
\hline 2(3H)-Dihydro-3-hydroxy-4,4-dimethylfuranone & 21.26 & Ether & $\times$ \\
\hline 5-Acetyldihydro-2(3H) furanone & 21.59 & Ether & \\
\hline 2-Methoxy-4-vinylphenol & 22.79 & Both & \\
\hline 5,6-Dihydro-6-pentyl-2H-pyran-4-one & 23.17 & Hexane & \\
\hline 2,6-Dimethoxyphenol & 23.41 & Both & $x$ \\
\hline 1-Acetylpyrrolidine & 24.43 & Ether & \\
\hline 2,3-Dihydrobenzofuran & 24.55 & Ether & \\
\hline 1,4:3,6-Dianhydro- $\alpha$-d-glucopyranose & 24.63 & Ether & \\
\hline Benzoic acid & 25.20 & Both & $\times$ \\
\hline 6-Ethoxy-1,2-dihydro-2,2,4-trimethylquinoline & 25.37 & Both & \\
\hline Benzeneacetic acid & 26.14 & Both & $\times$ \\
\hline Dihydro-4-hydroxy-2(3H) furanone & 26.32 & Ether & \\
\hline 1-(4-Hydroxy-3-methoxyphenyl) ethanone & 26.62 & Both & $\times$ \\
\hline 1-(4-Hydroxy-3-methoxyphenyl)-2-propanone & 26.74 & Both & $\times$ \\
\hline 2,6-Dimethoxy-4-(2-propenyl)-phenol & 27.27 & Both & \\
\hline 3,4-Dimethoxyphenol & 27.54 & Both & \\
\hline 4-(4-Hydroxy-3-methoxyphenyl)-2-butanone & 27.81 & Hexane & \\
\hline Hexadecanoic acid & 28.52 & Hexane & \\
\hline 3-(2-Hydroxyphenyl)-2-propenoic acid & 28.62 & Hexane & \\
\hline 4-Methoxybenzoic acid & 28.68 & Hexane & $\times$ \\
\hline 4-Hydroxy-9-fluorenone & 28.89 & Hexane & \\
\hline 4-Hydroxybenzaldehyde & 29.07 & Ether & $\times$ \\
\hline 4-Pyridinecarboxamide & 29.18 & Ether & $\times$ \\
\hline 4-Hydroxy-3-methoxybenzeneacetic acid & 29.22 & Ether & \\
\hline 1-(4-Hydroxy-3,5-dimethoxyphenyl) ethanone & 29.35 & Hexane & \\
\hline 4-Hydroxybenzene ethanol & 29.44 & Ether & $\times$ \\
\hline 4-Hydroxybenzene acetonitrile & 31.10 & Ether & $\times$ \\
\hline 1-Acetyl-9H-pyrido[3,4B]indole & 31.77 & Ether & \\
\hline
\end{tabular}

dimethyl-4-hydroxy-3(2H)-furanone, was found to be a direct conversion product of $\mathrm{D}$-fructose, thereby bypassing cleavage of the carbohydrate $[25,26]$. The compounds 2,5 -dimethylpyrazine and trimethylpyrazine are commonly found in the thermal processing of natural products. Both are present during the processing of maple syrup [27] and processed cocoa beans $[28,29]$, while trimethylpyrazine and not 2,5-dimethylpyrazine was found in dark chocolate [30], and roasted peanuts [31]. Both pyrazines compounds were found to be attractive to the Mexican fruit fly [32].

Some compounds found in Table 1 have been tested for a response from house flies using gas chromatography/electroantennogram detection (GC/EAD). This technique provides a means of screening compounds for biological activ- ity based upon electrical impulses from antennae when odorants bind to a receptor site. A positive GC/EAD response indicates likelihood that the odorant is detected by at least one antennal receptor; however, it does not provide the behavioral significance of the odorant response, i.e. whether the compound functions as a kairomone, pheromone, or allomone. From a study of pig manure volatiles, it was determined that butanoic acid elicited a positive response from house fly antennae, whereas acetic acid, pentanoic acid, hexanoic acid, and hexadecanoic acid did not produce a significant electrophysiological response [33].

A previous experiment involving the fermentation of blackstrap molasses followed by headspace analysis identified 2,3-dibenzofuran as one of the constituents [34], a compound 


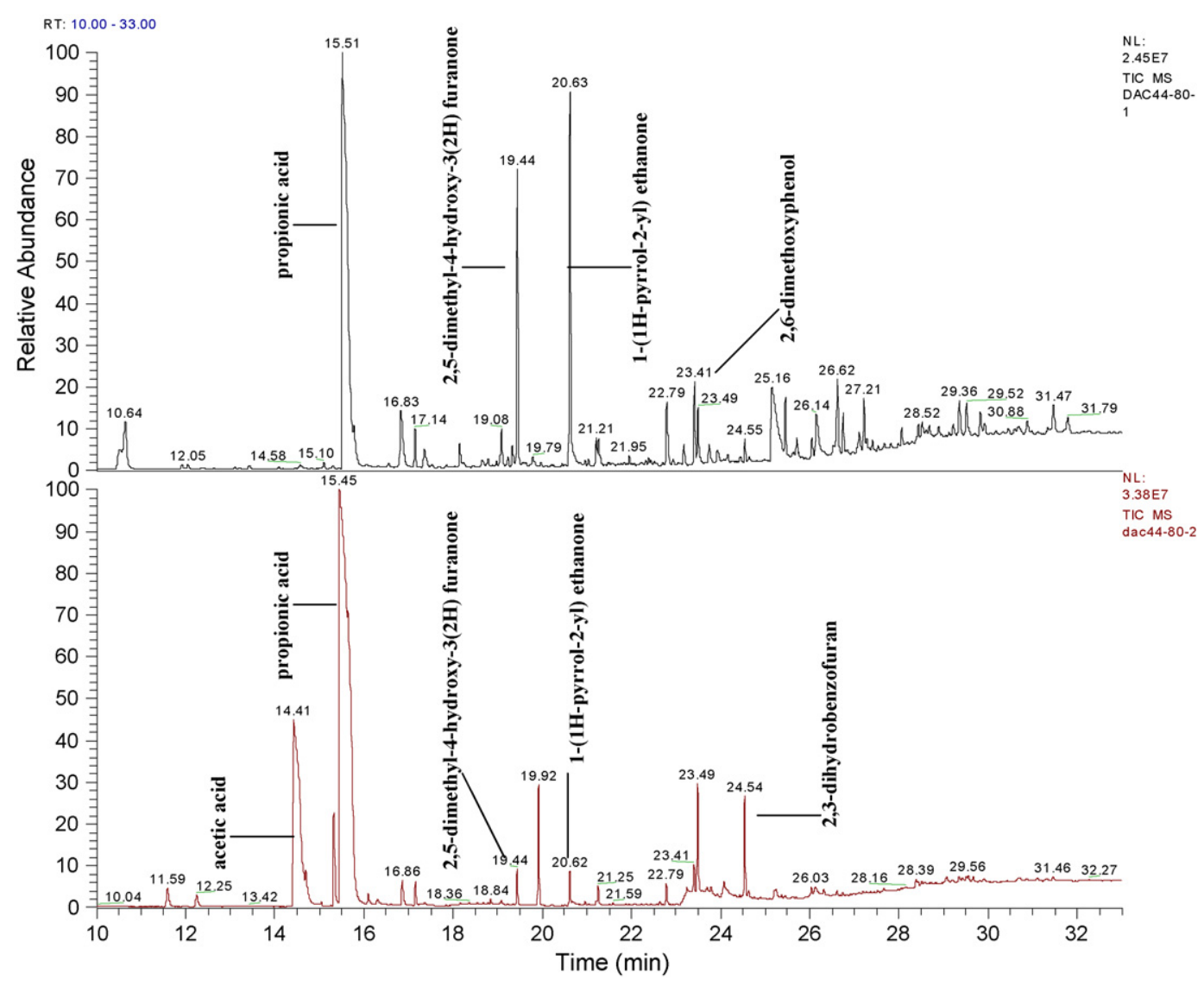

Fig. 1. Chromatograms of hexane (top) and ether extractions of blackstrap molasses feed.

which was also detected in this study (Table 1). Another study conducted on volatiles from cane molasses identified furfuryl alcohol, which was found in both hexane and ether extracts in this study [35]. This same study on cane molasses volatiles [35] yielded a large number of esters including ethyl formate, anisole, methyl benzoate, ethyl benzoate, and others that are indicative of microbial conversion products. Their formation is usually attributed to the presence of anaerobic bacteria that convert hydroxyl-groups to methyl and ethyl esters. Some examples of possible compounds of esterification found in this study include 2,6-dimethoxyphenol, 1-(4-hydroxy-3,5dimethoxyphenyl) ethanone, and 2-methoxy-4-vinylphenol. A counterargument to microbial activity in molasses was presented in a study that showed that acetic, butyric, propionic, and pentanoic acids, which were all found in this extract, were inhibitors of fermentation [36]. While those compounds might inhibit fermentation, there could be other microbial action taking place as shown by the presence of so many esters in these experimental extracts or concentrations of these carboxylic acids were too low to inhibit microbial degradation.

A study conducted on cane juice, the raw expressed liquid from sugar cane, yielded a list of 15 identified compounds, none of which were found in extracted or volatile samples from this study [37]. This suggests that many compounds present in blackstrap molasses are thermal degradation products of the abundant sugars found in this commodity. This conclusion is further supported by a study of sucrose pyrolysis products that listed furfural and 2-hydroxy-3-methyl-2-cyclopenten-1one, which were both major components found in extracted blackstrap molasses feed [38]. This same study suggested that one of the first intermediate compounds of sugar pyrolysis was 1,4:3,6-dianhydro- $\alpha$-d-glucopyranose, which was found in the ether extract of blackstrap molasses. An earlier study attempting to identify phenolic compounds in cane molasses found only one compound that matched the findings of this study, benzoic acid [39]. Since blackstrap molasses is heated longer than cane molasses, further conversion of intrinsic sugars and polyphenolic compounds must be occurring to produce some of the compounds found in Table 1. In comparison, the results of the extracted samples from this experiment were matched with a study that investigated the aroma compounds from citrus honey, and only furfural was found to be a major component in both sample matrices [40].

Analysis of volatile samples of blackstrap molasses yielded a number of organic compounds (Table 2, Fig. 2). Many of the compounds including acetaldehyde, ethanol, acetone, dimethyl sulfide, 2-methylfuran, 2-methylbutanal, and 2,3-pentanedione were also found in a study that analyzed volatiles of a sample of blackstrap molasses from South America [41]. Acetaldehyde and ethanol have also been identified in cane molasses [35] and both compounds have been identified as mild attractants to houseflies [12]. Analysis of extracted honey produced 2-methylfuran and 2,3-pentanedione [40], and both were found in the volatile analysis of blackstrap molasses. 
Table 2

Volatile organic components from blackstrap molasses

\begin{tabular}{lc}
\hline Compound name & Retention time (min) \\
\hline Acetaldehyde & 4.85 \\
Ethanol & 5.74 \\
Acetone & 6.07 \\
Dimethyl sulfide & 6.71 \\
2-Methylpropanal & 7.37 \\
2,3-Butanedione & 7.94 \\
2-Butanone & 8.16 \\
2-Methylfuran & 8.60 \\
2-Methyl-2-buten-2-ol & 8.80 \\
3-Methylbutanal & 9.62 \\
2-Methylbutanal & 9.88 \\
2,3-Pentanedione & 10.50 \\
Pentanal & 10.61 \\
Toluene & 12.64 \\
Dihydro-2-methyl-3(2H)furanone & 13.07
\end{tabular}

In bioassays, an average of $25.0 \pm 2.6$ [mean (SE)] flies were captured in molasses-baited containers after five minutes, compared with $4.0 \pm 0.8$ in the water controls (86.2\% response). Containers baited with hexane extract captured $14.4 \pm 3.0$ compared with $6.0 \pm 1.0$ (70.6\% response), indicating that the hexane extract retains most of the behaviorally-active olfactory cues found in the raw product. In tests with paired blanks, fly response was weak and indicated no preference for either side of the arena $(3.4 \pm 0.8$ versus $3.8 \pm 1.0)$. This reduction in house fly attractiveness to the hexane extract is likely due to the loss of some important volatile compounds from the rotoevaporation required to concentrate the sample. Because the hexane extract was so attractive to house flies, the ether extract was not bioassayed; however, both the hexane and ether extracts were analyzed by GC/MS.

The concentration of blackstrap molasses affects the biological attractiveness observed in house flies. A 50\% dilution of molasses in deionized water was used and elicited an average $86.2 \%$ attraction response from house flies. A previous field study showed that a $25 \%$ dilution of blackstrap molasses showed no statistical difference in the attraction compared to that of the commercially available Farnam bait [20]. However, laboratory olfactometer studies of the $10 \%$ and $1 \%$ dilutions

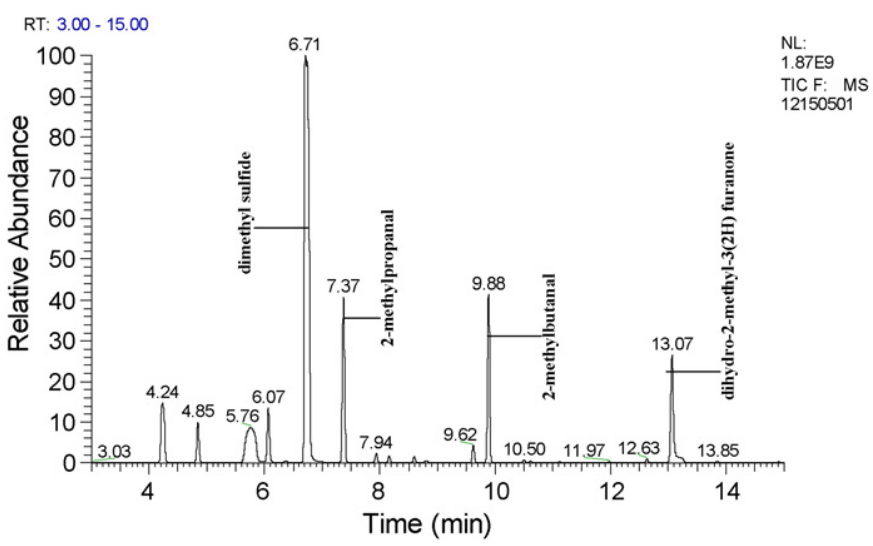

Fig. 2. Chromatogram of volatile components in blackstrap molasses. showed no significant difference from the deionized water control [12].

Further studies will be aimed at identifying the components responsible for attraction of house flies to fresh molasses and comparing the concentrations of these compounds to levels in fermented or microbially oxidized molasses. Fresh molasses has been successfully used as an attractant either by itself $[10,20]$ or in a mixture with other ingredients such as the Beltsville Bait [16]. Historically, fermented molasses has been used by poultry farmers in California to bait and kill house flies [14]. Since sugars are not very volatile, either volatile intrinsic components or degradation products of blackstrap molasses are expected to be the odor cues used by house flies to locate this food source.

\section{Acknowledgment}

The authors thank Dr. Chet Fields of the United States Sugar Corporation for technical advice on manufacturing blackstrap molasses in addition to supplying molasses directly from the production line, and also Mandi Falkner, ARS, Gainesville for preparing the extracted molasses samples. Funding for this research was provided by the Department of Defense through the Deployed War Fighter Protection Program.

\section{References}

[1] O.S. Levine, M.M. Levine, Rev. Infect. Dis. 13 (1991) 688

[2] K. Moriya, T. Fujibayashi, T. Yoshihara, A. Matsuda, N. Sumi, N. Umezaki, H. Kurahashi, N. Agui, A. Wada, H. Watanbe, Med. Vet. Entomol. 13 (1999) 214.

[3] M. Iwasa, S. Makino, H. Asakura, H. Kobori, Y. Morimoto, J. Med. Entomol. 36 (1999) 109

[4] M. Kobayashi, T. Sasaki, N. Saito, K. Tamura, K. Suzuki, H. Watanbe, N. Agui, Am. J. Trop. Med. Hyg. 61 (1999) 625.

[5] T. Sasaki, M. Kobayashi, N. Agui, J. Med. Entomol. 37 (2000) 945.

[6] A.R. Olsen, T.S. Hammack, J. Food Protection. 63 (2000) 958.

[7] L.S. Mian, H. Maag, H.V. Tacal, J. Vector Ecol. 27 (2002) 82.

[8] P. Escheverria, B.A. Harrison, C. Tirapat, A. McFarland, Appl. Environ. Microbiol. 46 (1983) 32.

[9] R. Fotedar, Acta Trop. 78 (2001) 31.

[10] L.O. Howard, The House Fly—Disease Carrier, Fredrick A. Stokes, New York, 1911

[11] D.A. Garrett, Ph.D. Thesis, Oklahoma State University, Stillwater, OK, 1965. p. 43.

[12] A.M. Frishman, J.G. Matthysse, Agricultural Experimentation Memo No. 394, Cornell University, Ithaca, NY, 1966. p. 21.

[13] M.S. Mayer, USDA Agricultural Handbook 403 (1971) 23.

[14] M.S. Mulla, Y.S. Hwang, E.C. Loomis, H. Axelrod, Proceedings Paper of the 46th Annual Conference of California Mosquito Vector Control Association. (1978) 60

[15] H.R. Willson, M.S. Mulla, Environ. Entomol. 2 (1973) 815.

[16] L.G. Pickens, R.W. Miller, G.R. Mowry, J. Med. Entomol. 10 (1973) 84.

[17] L.G. Pickens, R.W. Miller, J. Agric. Entomol. 4 (1987) 305.

[18] A.W.A. Brown, A.S. West, A.S. Lockley, J. Econ. Entomol. 54 (1961) 670.

[19] M.S. Mulla, Y.S. Hwang, H. Axelrod, J. Econ. Entomol. 70 (1977) 644.

[20] C.J. Geden, J. Vector Ecol. 30 (2005) 1.

[21] D.A. Carlson, M.S. Mayer, D.L. Silhacek, J.D. James, M. Beroza, B.A. Bierl, Science 174 (1971) 76.

[22] D.A. Carlson, M. Beroza, Environ. Entomol. 2 (1973) 555.

[23] G.P. Meade, J.C.P. Chen, in: G.P. Meade, J.C.P. Chen (Eds.), Cane Sugar Handbook, 10th ed., Wiley, New York, 1977, p. 43.

[24] W.W. Binkley, M.L. Wolfrom, Adv. Carbohydr. Chem. 3 (1953) 1.

[25] W. Schwab, J. Agric. Food Chem. 46 (1998) 2266. 
[26] M. Wein, E. Lewinsohn, W. Schwab, J. Agric. Food Chem. 49 (2001) 2427.

[27] E. Akochi-K, I. Alli, S. Kermasha, J. Agric. Food Chem. 45 (1997) 3368.

[28] P. Hashim, J. Selamat, K. Muhammad, A. Ali, J. Sci. Food. Agric. 79 (1999) 987.

[29] E.S. de Brito, N. Narain, N.H.P. Garcia, A.L.P. Valente, G.F. Pini, J. Sci. Food Agric. 82 (2002) 534.

[30] C. Counet, D. Callemien, C. Ouwerx, S. Collin, J. Agric. Food Chem. 50 (2002) 2385.

[31] M. Leunissen, V.J. Davidson, Y. Kakuda, J. Agric. Food Chem. 44 (1996) 2694.

[32] D.C. Robacker, R.J. Bartlet, J. Chem. Ecol. 23 (1997) 2897.

[33] A.A. Cosse, T.C. Baker, J. Agric. Entomol. 13 (1996) 301.
[34] A.M. El-Sayed, V.J. Heppelthwaite, L.M. Manning, A.R. Gibb, D.M. Suckling, J. Agric. Food Chem. 53 (2005) 953.

[35] M. Yokota, I.S. Fagerson, J. Food Sci. 26 (1971) 1091.

[36] G.A. Dierssen, K. Holtegaard, B. Jensen, K. Rosen, Int. Sugar J. 58 (1956) 35.

[37] Y. Tokitomo, A. Kobayashi, T. Yamanishi, Agric. Biol. Chem. 48 (1984) 2869.

[38] R.R. Johnson, E.D. Alford, G.W. Kinzer, J. Agric. Food Chem. 17 (1969) 22.

[39] T. Hashizume, T. Yamagami, Y. Sasaki, Agric. Biol. Chem. 31 (1967) 324

[40] E. Alissandrakis, P.A. Tarantilis, P.C. Harizanis, M. Polissiou, J. Sci. Food Agric. 85 (2005) 91.

[41] M.A. Godshall, E.J. Roberts, M.G. Legendre, J. Agric. Food Chem. 28 (1980) 856 